Notre Dame Law School

NDLScholarship

Natural Law Forum

$1-1-1959$

\title{
An Examination of the Thomistic Theory of Natural Moral Law
}

Kai Nielsen

Follow this and additional works at: http://scholarship.law.nd.edu/nd_naturallaw_forum Part of the Law Commons

\section{Recommended Citation}

Nielsen, Kai, "An Examination of the Thomistic Theory of Natural Moral Law" (1959). Natural Law Forum. Paper 39.

http://scholarship.law.nd.edu/nd_naturallaw_forum/39

This Article is brought to you for free and open access by NDLScholarship. It has been accepted for inclusion in Natural Law Forum by an authorized administrator of NDLScholarship. For more information, please contact lawdr@nd.edu. 


\section{AN EXAMINATION OF THE THOMISTIC THEORY OF NATURAL MORAL LAW*}

Kai Nielsen

Theories of natural moral law have deep roots in our culture. They have emerged again and again in our western tradition, not, however, without important variations. They are less appealing in times of social and political stability than in times of social crisis. In times when man turns against man, voices are always raised to remind us that man by virtue of his very humanity has certain inalienable rights and certain absolute correlative obligations to his fellow man. Like Antigone, we appeal to moral laws that transcend an ethnocentric "closed morality" of social pressure. In our recent history, liberalism, both theoretically and practically, has faced dilemmas; liberalism has been subjected to penetrating and varied challenges. Saddled with this situation, some theologizing political scientists have hoped to find in the classical doctrine of the natural moral law a "new" and more secure moral foundation for democracy and a solution to the modern liberal predicament. As incisive a student of the changing human scene as Walter Lippmann, has in his The Public Philosophy attempted a modern adaptation of the classical natural moral law theory as the way to wisdom in our social life and politics. By return to a secure foundation in the classical tradition of natural moral law, we can underwrite democracy and escape the quandary of "the masterless man" searching-perhaps unconsciously-for his "soul" or for a point of view for which he can live and die. A social ethic, firmly grounded in the natural moral law, will supply a dynamic standard to enable us to root out the modern malaise that says, with James Joyce, "Ours is an age of exhausted whoredom, groping for its God."

I believe the philosophical and ethical theory operating in these classical natural moral law theories to be basically mistaken. Therefore, I do not believe they can serve as adequate theoretical justifications for democracy or for anything else. Rather than criticize Lippmann explicitly, I will turn here to Lippmann's mentors, that is to say, I shall turn to the wellarticulated and thoroughly developed theory of natural moral law that we find in Aquinas and in some contemporary Thomists. In this con-

* I should like to thank Professor Warren C. Hamill of St. Anselm's College for his helpful criticism of an earlier draft of this essay, though I should not like to suggest that he would agree with my criticisms of Aquinas. 
nection, I shall pay particular attention to the arguments of Jacques Maritain and F. C. Copleston. 1

It is important to note that I am not contending it is unintelligible to speak in some vague and unanalyzed sense of a natural good or goods that men generally incline toward. ${ }^{2}$ I am only contending here that the scholastic, philosophical theory about natural law is in some basic respects unsatisfactory and, in the last analysis, unintelligible. I neither assert nor deny there are some basic moral evaluations common to the human animal. I should think that there are some, but the problem is too amorphous to be settled as yet. We need first a detailed analysis of what is meant by the terms, 'common good,' 'pan-human good' or 'basic moral evaluations,' and we need a thorough comparative anthropological investigation of what moral appraisals are actually made in radically different cultures. To take a stand pro or con, prior to such investigations, is unreasonable. I shall try here to fairly state and criticize the Thomistic theory of natural moral law.

I shall do this in the following way. In I, I shall make some remarks about what has been taken by the Thomists to be the proper setting for an adequate statement of the natural moral law theory. Then in II and III, I shall turn to the epistemic side of Thomistic ethical theory. In II, I state and evaluate Maritain's conception of "knowledge through inclination" and in III, contrast Thomas' ethical theory with theological voluntarism and criticize the Thomistic concept of something being self-evident in itself. In IV, I shall elucidate what Aquinas means by 'natural moral law' and contrast it with his other conceptions of law. In V, I shall state and then critically comment on the primary and secondary precepts of the natural moral law. In VI, I shall first discuss two standard difficulties with the natural law theory and then turn to two less frequently voiced, but more radical criticisms, that - to my mind - take us to the heart of the matter. Finally, I shall turn in VII and VIII to some puzzles about morality and teleology that might, in the light of my arguments in VI, prove worrisome.

1. The basic texts involved are St. Thomas Aquinas, Summa Theologiae I-II, Qq. 90-108; and Summa Contra Gentiles, Book III; Copleston's major treatment occurs in F. C. Copleston, Aquinas, ch. V (Baltimore, 1955). For Jacques Maritain's most recent extended examination, see his Man and the State (Chicago, 1951); The Range of Reason (New York, 1951); and Natural Law and Moral Law, in Moral Principles or AcTION 62-76 (ed. by R. N. Anshem, New York, 1952). I have also drawn from some unpublished lectures given by Maritain at the University of Toronto in 1952 . For a brief but excellent summation of Aquinas' view see Clifford G. Kossel, S. J., The Moral View of Thomas Aquinas, Encyclopedia of Morals 11-23 (ed. by V. Ferm, New York, 1956). 2. The Oxford moralist, P. H. Nowell-Smith, makes an analysis of natural good that seems to me a step in the right direction. P. H. Nowel.L-S mith, Eтhics 171-82 (Baltimore, 1954). Note also my remarks at the end of my essay, Reason and Morality, 28 Journal of Higher Education 271-275 (1957). 
Aquinas and contemporary Thomists like Maritain and Copleston give a large place to reason in their Christian ethical theory. They argue that if man doubts God's revealed Word, he can by the use of his reason come to know that God exists and that there are certain natural moral laws carrying obligations. By his reason alone, man can know certain natural goods. Aquinas' approach here bears the stamp of Aristotle's "commonsensical philosophy of ethics."

Though "metaphysical ethics" is now out of fashion in most quarters, Aquinas' theory has no plausibility at all apart from his conception of the nature of the universe. ${ }^{3}$ In evaluating Aquinas' ethics we must keep constantly in mind his physics and cosmology. As Copleston remarks, Aquinas "sees the moral life in the general setting of the providential government of creatures" (p. 212), that is to say, Aquinas, like Aristotle, thinks the universe is purposive. It has a destiny and a rationale. The universe is not just some vast machine or conglomeration of atoms swirling in the void. The end of all activities in nature, says Aquinas, is God. In medieval physics, it is believed that all natural motions are just so many attempts to reach the changeless. Sublunar substances seek re-establishment in their proper places. Celestial motions cannot falter; they return upon themselves in perfect circles. Nevertheless, they are still motions. Only God is absolutely motionless and changeless. All motions and all things try to attain God, the motionless or changeless Being. We know that knowledge of and union with God is man's highest good; all other goods are finally instrumental to that good. But as Sisyphus sticks to his job with his stone, we ineluctably quest for that highest good. We know God exists, but we contingent, changing creatures never obtain God or knowledge of His essence in this life. But, unlike Sisyphus, we mortals have a surcease from striving, for after death there is a complete apprehension of God in His very essence.

Maritain emphasizes that conceptions of the natural moral law cannot be secularized, as in Grotius or Paine, without cutting out their very heart. The natural moral law theory only makes sense in terms of an acceptance of medieval physics and cosmology. If we give up the view that the universe is purposive and that all motions are just so many attempts to reach the changeless, we must give up natural moral law theories. One might say, as a criticism of the Thomistic doctrine of natural moral law, that since medie-

3. Kossel remarks: "The moral science of Aquinas is deeply rooted in metaphysics and theology." Kossell, op. cit. supra, note 1 at 12 . 
val physics is false then it follows that natural moral law theory must be false. While agreeing with this criticism, I think it is too short and too easy a way out to carry complete conviction. Contemporary Thomists would like to say that somehow the medieval view of cosmology or metaphysics is distinct from physics, and though the physics is false, the cosmology is still true. This seems to me just an evasion. If the word 'cosmology' means anything at all, it seems only to denote bad armchair physics. The so-called disciplines of cosmology and metaphysics have made no progress in discovering the categorial features of the world. This is so partly because of the very unsettled and indefinite signification of the words 'cosmology' and 'metaphysics.' In such a situation, it seems to me quite unrealistic to think we can use such disciplines as a basis for anything very substantial.4 In this connection, it might be noted, incidentally, that Copleston, in his recent book, Contemporary Philosophy, is extremely cautious in his claims for metaphysics. ${ }^{5} \mathrm{He}$ rightly criticizes many things in contemporary and analytic philosophy, but in the process, he seems to have been bitten by the empiricists' bug! I shall not, however, rest my argument on this general blast against speculative philosophy though I should like to remark that my contention does not turn on a logical positivist rejection of metaphysics as nonsense. There may be, as Peirce suggests, both good and bad metaphysics and metaphysical methods.

Leaving aside all talk about the adequacy or inadequacy of metaphysics, let us look directly at Aquinas' moral philosophy. Aquinas believed that the good is somehow the normal. It is found by observation; that is to say, it is to be discovered by studying man's inclinations and reflecting on them. It is to be seen by apprehending what life really is. It is important to note, however, that this is an odd kind of "seeing" or "apprehending." As Maritain makes perfectly clear, it is a direct, immediate, nonconceptual "knowing through inclination" or "knowledge through connaturality." 6 And it is important to remember here that Maritain is not just trying to urge a view of his own but is also trying to elucidate what Aquinas really meant when he said we have knowledge of the natural moral law.

4. Sidney Hook's critique of Thomism on this point seems to me essentially correct. See Sidney Hook, Scientific Knowledge and Philosophical Knowledge, 24 Partisan Review 215-34 (1957).

5. See particularly ch. V and XII.

6. See Jacques Maritain, The Range of Reason, ch. III (New York, 1952). See also his contribution, Natural Law and Moral Law, in Moral Principles of Action (ed. by R. N. Anshem, New York, 1952). 
Let us look a bit more carefully at this doctrine, for it is, according to Maritain, central to the Thomistic theory of natural moral law. Unfortunately, as Maritain also emphasizes, it is an extremely obscure doctrine. This so-called "knowledge through inclination" seems unlike what we ordinarily call "knowledge." It seems more like a feeling or an attitude. I am at a loss here to find an intelligible use for "knowledge," and I am far from sure that we can see clearly from Maritain's account exactly what it is that he wishes to say. (Here he could use a few lessons from G. E. Moore.) So in setting forth this aspect of Maritain's doctrine, I will be forced to use quotations liberally.

We discover first that knowledge through inclination is entirely nonrational and nonconceptual, even though produced in the intellect. ${ }^{7}$ It is important, according to Maritain, for two reasons: 1) it "obliges us to realize in a deeper manner the analogous character of the concept of knowledge" and 2) it is important because of the role it plays in our knowledge of human existence. ${ }^{8}$ It is obviously not a deductive kind of knowledge, and it is not knowledge through sense experience or speculative knowledge through "intellectual intuition." 9 Maritain remarks: "the intellect is at play not alone, but together with affective inclinations and the dispositions of the will, and is guided and directed by them." ${ }^{10}$ It is knowledge expressing the inner propensities of our being. It may be "incapable of giving account of itself, or of being translated into words." 11 We find it occurring in mystical experience and in "poetic knowledge," but the best paradigm for it is in moral knowledge. For Aquinas, our philosophically unmediated moral experience is the prime example of knowledge through inclination. In a very puzzling passage, Maritain remarks of Aquinas:

It is through connaturality that moral consciousness attains a kind of knowing - inexpressible in words and notions - of the deepest dispositions - longings, fears, hopes or despairs, primeval loves and options involved in the night of the subjectivity. ${ }^{12}$

Maritain does not deny that the facts are relevant to moral appraisal, but he adds that the moral agent must take into account "secret elements of evaluation which depend on what he is, and which are known to him through

7. Maritain, The Range of Reason 22 (New York, 1952).

8. Ibid.

9. Id. at 29 .

10. Id. at 23 (italics mine).

11. Ibid.

12. Id. at 26 (italics mine). 
inclination, through his own actual propensities. . .."13 Moral judgments which express the natural moral law are not known through any "conceptual, discursive, rational exercise of reason." 14 Instead, through inclination we grasp that what is in line with pervasive human desires and wants is good, and what conflicts with that is bad. Moral philosophy does not discover the moral law, though (in some unspecified sense) it critically analyzes and elucidates moral standards. ${ }^{15}$ Objective moral standards (ultimately the natural moral law) are known immediately through inclination.

In this murky doctrine of "knowledge through inclination" there is (so far as I can understand it) a good bit that is true as well as a good bit that is false. I shall first remark on what seems to me true in the theory and then I shall turn to what I take to be wrong with Maritain's theory.

First, Maritain is right in claiming that the concept of knowledge has an analogous character, that is to say, the word "knowledge" gets used in several different but not unrelated ways for several different purposes. My only question here is whether Maritain has either elucidated one of its many common uses or clearly stipulated a new use. Secondly, Maritain is also right (following Aristotle) in regarding moral knowledge as a kind of practical knowledge and in claiming that moral philosophy cannot by itself supply standards of moral appraisal. Surely, if a man had never experienced pain, remorse, deprivation, desire and the like, moral distinctions could have no meaning for him. A completely unmoved spectator of the actual would and could make no moral judgments or reflective moral appraisals. Furthermore, moral appraisals are practical in the sense that they are to guide action and alter behavior and not just to describe a state of affairs. But this claim has been clearly explicated from within an essentially empiricist point of view without any of Maritain's obscure constructions. ${ }^{16}$

Let us now consider difficulties in Maritain's conception of "knowledge through inclination." First, the work of philosophical analysts like Ryle and Wittgenstein makes it questionable whether one can sensibly speak of a kind of knowing "inexpressible in words and notions." To call something that cannot be conceptualized or expressed "knowledge" seems like an early retreat into a kind of obscurity that makes philosophical appraisal impossible. How can we, if we doubt there is really such a kind of knowing, rationally resolve this doubt? Or, even more basically, what is it that Maritain is claim-

13. Ibid.

14. Id. at 23 .

15. Id. at 28 .

16. Philip Blair Rice has recently developed a renovated ethical naturalism in which this is one of the cornerstones of his philosophy. See Philip B. Rice, ON The KNowledge of Good and Evil (New York, 1955); and P. H. Nowell-Smith, Ethics (Baltimore, 1954). 
ing? It is a truism to say that in philosophical appraisal we must necessarily deal with what is expressible.

My second critical point about his doctrine of knowledge through inclination is connected with the last part of my second positive point. In effect, Maritain sets forth a naturalistic theory at the foundation of natural moral law: ${ }^{17}$ what man strives for is good and what man avoids is bad. But at the same time he claims that only a supernatural sanction will do for morality and will avoid the chaos of our time. Yet, on his doctrine of knowledge through inclination and on his natural moral law theory, the man in moral perplexity needs only to observe the desires and wishes of his fellow man and by seeing what they generally seek he will know what is good and what he ought to do. It is very difficult to see how this doctrine differs very much from that of Russell (in his Human Society in Ethics and Politics) and Hume where they claim that reason is and ought to be the slave of the passions and that the fundamental data for and basis of ethics are the emotions, passions, and impulses. The Thomistic label "knowledge through inclination" only serves to label the baby "legitimate" in the eyes of the supernaturalists. And to call attention to the distinction between jus gentium and jus naturale is not at all to the point here, for it is claimed that by noting the actual pervasive desires and wants of the human animal we can at least dimly come to know the natural moral law.

\section{III}

Maritain, however, would not wish to accept this reduction - there are other elements in his theory that run counter to that and may provide him with a way out. For Aquinas and for Maritain good is not simply what God wills, as the theological voluntarists claim. God's intellect is logically prior to His will, according to St. Thomas. He wills the good because it is good. Aquinas' medieval opponents, Scotus and Ockham, hold different views. Scotus claims that God's will is prior to His intellect. In understanding human good, we must look to what man wills or strives for. William of Ockham goes all the way with this theological voluntarism. Something is good simply because God wills it. Goodness is in the will and not in any order of being or reality. What is right or wrong morally is not subject to rational proof as in Aquinas. Many people feel that this voluntarist view leads logically to moral skepticism. ${ }^{18}$ It can be argued plausibly that on the one hand volun-

17. See, for example, William Frankena, Ethical Naturalism Renovated, 10 The Review of Metaphysics 457-73 (1957).

18. See E. W. Hall, Modern Science and Human Values 289 (Princeton, 1956). 
tarism leads to Luther, Kierkegaard, and Barth, and on the other, to Hume's and Russell's view that reason is and ought to be the slave of the passions, the basic difference being that the former are supernaturalists and the latter are not. But for Aquinas, as for the Stoics, good is somehow in the very nature of things. The highest goodness is an attribute of God's very essence. This essence we know only after death. But we know now that God is (as opposed to knowing what $\mathrm{He}$ is); and we apprehend the natural moral law as the part of the eternal law that God allows us to understand with our reason. Our knowledge of it is not precise, but we genuinely know the unchangeable and eternal good, though we must remember this is "knowledge through inclination." This natural knowledge of good and evil is far from clear, but we do have it; and it is well to remember that this practical knowledge is claimed to be certain though cognitively unclear knowledge. By this, Aquinas (as well as Maritain) means that the natural moral law is self-evident in itself though it may not be self-evident to us.

We must, however, look into this peculiar claim of self-evidence. The uses of this word are many and varied. It is tempting to take an empiricist and pragmatist line and argue that all talk of "self-evidence" is useless or absurd because "self-evident truths" are tautological and existential statements are all less than certain. I do not - at least not here - want to make that strong claim, but only to argue that talk of "self-evidence in itself," as an idea that corresponds to the idea of the Divine Craftsman, does not make for clarity. On such a theory, statements can be self-evident in themselves quite apart from any human knowledge of them. Maritain emphasizes that it is God's Reason, not man's reason, that is the source of the natural moral law. For its authority natural moral law depends solely on "Divine Subsisting Reason." The cardinal error of Grotius and the philosophes (old and new) is to take natural law to be a "law of human nature" as deciphered by human reason. To do so is to make the egregious error of substituting human authority for Divine Authority, human reason for Divine Reason, as the standard for moral good. Natural moral laws are indeed rationally self-evident, but they are selfevident to God and not necessarily to man. Even assuming we can make sense of all this talk, such a conception of self-evidence still does not help us out at all, for how do we know, as moral agents faced with practical problems, which of the many moral imperatives are the self-evident laws of God? The important thing is to have something self-evident to us, or at least some reliable knowledge of God's natural moral law. With a natural moral theory we can, supposedly, bypass the appeal to faith made by neo-orthodoxy and by Christian existentialism. In Thomistic ethics (old and new) we have held out to us the promise of a rational ethic and rational decision procedure for 
what we ought to do in particular situations; but in reality, since human reason is not adequate to decide what is a natural moral law or what is or is not self-evident in such a situation, we are no better off with such a theory than with the severest fideism.

"Natural moral laws are self-evident in themselves" and "Natural moral laws are known through inclination" are two exceedingly obscure statements that raise more problems than they solve. The doctrines they express hardly function as aids to a rational solution of the problems connected with our knowledge of good and evil.

\section{IV}

Now let us see a little more specifically what Aquinas and his contemporary followers mean by "natural moral law." Perhaps here we will at least discover how to start out. The natural moral law is distinct from the laws of nature in the scientific sense of "law of nature." A law of nature is a hypothesis. It functions predictively, though there is no need to say this is all the laws of nature do. But they must at least do this. If something is a law of nature we must be able to infer from it "If so and so is done, such and such will happen." Natural moral law, on the other hand, is normative and at the same time somehow part of the very structure of the universe. It not only says what is the case, but it says what ought to be the case.

Natural moral law, for Aquinas, is not merely what is on the books. This he calls positive law. But he argues that even positive law is genuinely law only when it does not conflict with natural moral law. Law, for Aquinas, is essentially a normative or a moral notion. He defines a law as "an ordinance of reason for the common good, promulgated, and emanating from him who has care of the community." Certain elements should be noted in his definition. 1) An ordinance is a precept, or a rule, saying so and so must or should be done. It is meant to guide conduct and not just tell us what has been done, is being done, and will be done; rather it tells us that something ought to be done. 2) It is a rational precept, not just a command. Yet it carries an obligatory or imperative force. 3) It is for the general good or happiness of the community. It is not just any command, and it is not just for some partial good. 4) It must come from a legitimate authority. 5) It must be publicly stated or proclaimed.

There are four basic kinds of law for Aquinas (natural moral law is, of course, one of these). First, there is the Eternal Law. The Eternal Law is God's law or blueprint for the universe. It is law governed by Divine Reason. It emanates from God as Sovereign and is promulgated by Him for the good of His Creation in several ways. The natural moral law is that part of the 
Eternal Law that man can apprehend with his unaided reason. It is not a creation of man's reason, but emanates from God's reason. Man's reason is quite passive with respect to the natural law. Man does not alter it or change it. Man is not the measure of all things. Rather, God is the measure of all that is and of all that is good. Mankind can apprehend this good, but he does not create or alter it, even by his collective decisions. (It is crucial to recall, as I pointed out in II, the nature of this "apprehension." It consists in what Maritain called "knowledge through inclination.") This natural moral law is the second kind of law. Divine Law is that part of the Eternal Law which God makes known through Divine Revelation and the like. It is not grasped by man's reason but is given to man as an Eternal Truth of Divine Revelation. The fourth kind of law is the human law. The particular precepts for the common good devised or fashioned by human reason are called human laws. These laws are not just given to us but they are the expression of human reason and decision. Human law, however, while not derived from natural moral law must be compatible with it. If a human ordinance conflicts with the natural moral law, it is a perversion of the natural moral law. One of the natural laws states that man must seek to preserve his own being. If we had a particular rule that said "All students who flunk from college must commit suicide," it could not be a human law, for it is incompatible with the natural law that "We ought to preserve our lives." A human law (to use Maritain's example) that is compatible with the natural moral law is the law that "people must stop at red lights - go at green lights." This human law is completely conventional and relative. Yet it is important that we have such a convention and that it is compatible with the natural moral law.

We should not forget that all these laws are either moral laws or they are directives that must be in accordance with moral laws. They are, in their proper spheres of application, guides for conduct. The natural law, Divine Law, and Eternal Law are unalterable and eternal. They are basic moral truths that hold as truths irrespective of any feelings or emotions on our part. They are binding on our conscience and we have a duty to obey them whether we have favorable attitudes toward them or not. And the human animal can know with absolute certainty, according to the Thomists, that certain natural moral law precepts are true. Our "knowledge" here is not "discursive knowledge" but that strange, immediate, "nondiscursive knowledge" Maritain calls "knowledge through inclination."

When we read Aquinas himself, and do not reflect on the sense of "knowledge" relevant here, we are easily led to believe that a claim is being made that, in some plain sense of "knowledge," we have certain knowledge of some eternal moral truths. But, as I shall try to show in V and VI, if we take 
"knowledge" in any of its ordinary senses it becomes exceedingly doubtful if we have any such knowledge of eternal moral truths. Faced with these difficulties it is natural to try to construe "knowledge" in a different way, as "knowledge through inclination," but then, as I have indicated, we end up by using the mark (token, sign-vehicle) "knowledge" in a very different way from the way we normally use it, while still keeping all the honorific features of "knowledge." We have, in short, made a persuasive definition. And when we actually keep in mind what is counting as "knowing moral laws" here, have we really a more objective claim about the foundations of morality than we have in Hume or Russell? Indeed we have a claim that sounds more objective than Hume's or Russell's, but when we consider the special way we "know" these laws (and this is our sole evidence for them) is it really any more objective than these "subjective views" that Thomists so frequently deplore?

Let us now consider the actual precepts of the natural moral law. "Good is to be done and gone after, and evil is to be avoided" is the primary natural moral law from which all others are derived, and it is the first principle of practical reason. ${ }^{19}$ Aquinas and his contemporary followers insist that all the other natural laws are based on this vacuous first principle of natural moral law. This, of course, is a very weak base indeed. For, unless we assign some denotation to the word "good," as used above, this first principle of the natural moral law would be completely compatible with the most extreme kind of relativism. But from the first principle of the natural moral law we cannot determine what the denotata or criteria of application of "good" will be. All we can conclude from this primary principle is that if something is good we have to seek it. It does not tell us what to seek. ${ }^{20}$ (Is Aquinas' statement here really anything more than a bit of linguistic information, disguised because it is stated in the material mode? Is Aquinas, here, really saying anything more than "If we call something 'good' then we must also say that it is something that is to be sought, everything else being equal"? But this informs us about our linguistic behavior; it hardly gives us the foundation of an objective rational ethic that will save us from the "dark night of subjectivity.")

Our knowledge of the other natural moral laws is much less certain. We know them (as Maritain most emphatically argues) immediately and non-

19. Practical reason is reason that is concerned with what is to be done. See John Ladd, Reason and Practice, in The Return to Reason (ed. by John Wild, New York, 1951). 20. Copleston, Aquinas 214-5 (Baltimore, 1955). 
conceptually by natural inclination. They are the ends we necessarily seek in virtue of our very humanity. We might list the ones Aquinas mentions, stating them clearly as normatives, so as to bring out their moral force.

1. Life ought to be preserved.

2. Man ought to propagate his kind.

3. Children ought to be educated.

4. Men ought to know the truth about God.

5. Man ought to live in society.

6. Ignorance ought to be avoided.

7. Offense ought not to be given unnecessarily.

These are all supposedly based, in some manner, on man's natural inclinations. It is claimed they are based on human nature. However, according to Aquinas, not all our inclinations are natural inclinations, for some can be "corrupted by vicious habits," and again the natural knowledge of good in them (people with vicious habits) is "darkened by passions and habits of sin." Aquinas is contending that there are some cross-cultural or pan-human characteristics that we might use in constructing a definition of "human nature." Like Plato, Aquinas is claiming that man is distinguished from the other animals by his ability to reason. If man examines his natural inclinations, he will discover that there are certain unalterable pan-human natural moral laws. Copleston states Aquinas' argument here in the following manner: "For although man cannot read off, as it were, eternal law in God's Mind, he can discern the fundamental tendencies and needs of his nature, and by reflecting on them he can come to know the natural moral law." (p. 213) Copleston continues: "Every man possesses also the light of reason, whereby he can reflect on these fundamental inclinations of his nature and promulgate to himself the natural moral law. ..." (p. 213) Purely natural man is not left in ignorance of the eternal law which is the ultimate rule of all conduct. The natural law part of the eternal law is not simply a Divine Fiat. Rather, we moral agents recognize its inherent rationally binding force. Though the first principle of natural law only tells us that good is to be done and evil is to be avoided, we give concrete content or non-zero denotation to our concept of good and evil "by examining the fundamental natural tendencies or inclinations of man." (p. 215) By examining man's nature and natural inclinations one can discern the good for man in the natural order.

Now, St. Thomas does distinguish between primary and secondary precepts of the natural moral law. The secondary precepts are not relative. But they do have only a limited contextual application, that is, they apply only to certain classes of acts. As Copleston remarks, what Aquinas means in say- 
ing that they can be changed is that such natural moral laws are altered when the circumstances of the act may be such that it no longer falls into the class of actions prohibited by the precept. Copleston uses the following example: "We can say in general that if someone entrusts his property to us for safekeeping and asks for it back, we ought to return it. No sensible man would say that if someone entrusts us with a knife or a revolver and asks for it back when he is in a state of homicidal mania, we are obliged to return it." (p. 219 ) Copleston then generalizes: "In its general form, however, the precept remains valid. We can say with truth that Aquinas believed in a set of unalterable moral precepts." (p. 219)

Maritain, though he makes a great show of wishing to square Aquinas' theory with the facts of moral relativity, does not seem to go beyond this above position in any significant manner. For Maritain there are certain fundamental "dynamic schemes" of natural moral law that are unalterable and are universal. In particular contexts they are subject to an "indeterminate expression." In fact, the same natural moral law can have different and distinct "indeterminate expressions," although they all must be compatible with the more general rule. The general rule is not changed. Unfortunately, the only examples Maritain gives us of culturally relative moral rules are rules of human law or positive law. However, no one questions their relativity or conventionality; what we want to know is what he would say about the actual and anthropologically confirmed exceptions to all seven of Aquinas' natural moral laws listed above. (Since this could conceivably be read as an admission on my part that we can derive an "ought" from an "is," it is more precise - though more cumbersome - to say: "Aquinas' claim that natural moral laws are expressions of the natural inclinations of all men conflicts with the anthropological claim that these are not always and everywhere expressions of natural inclinations.") No doubt he would say such inclinations, when they occur, are perverted or primitive. But this begs the question, for it is only by at least an implicit reference to a moral standard that we can determine which rules are "perverted," "primitive," or "corrupt." The natural moral law theorist, however, is supposedly building a normative ethic on man's actual natural inclinations, rather than on the inclinations of certain men called "good or non-perverted men." If the natural moral law theorist is to be consistent, he cannot simply proclaim a standard of moral appraisal and then say that all those who do not act in accordance with it are perverted or evil. Instead, the standard is supposed to come somehow from the very feelings and inclinations of all men. 
The above are only some of the puzzles engendered by the Thomistic theory. As clear as Aquinas' kind of theory may seem the first time around, it becomes far more difficult to comprehend after a closer look. Its taxonomic structure hides fundamental confusions, though on Aquinas' behalf it must be said that they were confusions which might naturally arise in his cultural context.

In pointing up these difficulties, I shall first turn to two standard difficulties that have been traditional stumbling blocks for students of natural moral law theories. I do not think these are the most basic difficulties, but I do think these standard difficulties are genuine and need looking into. I doubt that they can be answered satisfactorily from within the Thomistic position of natural moral law. I shall examine them first and then turn to what I regard to be the two more philosophically interesting and more basic difficulties in the natural moral law theory.

The first standard difficulty emerges when we compare the natural moral law theory with some of the things now being said in social psychology. It is frequently said that from the point of view of science, there is no such thing as an essential human nature which makes a man a man. The concept of human nature is a rather vague cultural concept; it is not a scientific one. ${ }^{21}$ While I think this criticism is surely debatable, it does raise a problem for the natural moral law theory since it is clear that the statement, "there is an essential human nature," is not the obvious, self-evidently true statement Aquinas and his contemporary followers take it to be.

The second standard criticism is a stronger one. It appeals to the facts of cultural relativity. If we go to actual cultures and study them, we find that all of the natural moral laws listed above by Aquinas are broken somewhere by some people. If it is answered, "Well, most cultures obey the above rules," two replies can be made.

First, it can be said that the reply in itself assumes that what most people find natural and better, is natural and better. To assume this, however, is to presuppose the value of a naive kind of democracy; we determine what is good by counting noses or by a Gallup Poll. Moral issues become vote issues. Aquinas, of course, would not wish to say they are "vote issues." Moreover,

21. Otto Klinberg, Social Philosophy (New York, 1940). On the other hand, A. H. Maslow and Weston LaBarre, along with others, have spoken in a supposedly scientific sense of "a human nature." See A. H. Maslow, Motivation and Personality (New York, 1954), and Weston LaBarre, The Human Animal (Chicago, 1954). 
why must we accept this "democratic" standard as our ultimate standard? If we say that people simply do accept it, we not only make a statement that is anthropologically false, but we also go in a circle. We use our democratic standard to establish our democratic standard. Secondly, it is the case that for the natural moral laws which are fairly concrete, there is not this majority agreement. If we turn to the more general natural moral laws, we find that they are so vague that they hide all sorts of differences that both parties would regard as crucial. As anthropologists, like Ralph Linton, have pointed out, all cultures have a concept of murder. But if we try to give the concept of murder some specific content which would cover its use in all cultures, we run into difficulty. While all cultures agree that murder is wrong, this is completely compatible with the Eskimos' killing members of their family if they do not feel they can make it through the winter; or with infanticide in Polynesia and Greece; or with the old Scandinavian habit of clubbing one's older ancestors to death so that they may go to Valhalla. But for these people this killing is not murder which is by implicit definition wrong. Just what will count as murder in the given culture varies radically. To say that all cultures have a concept of murder tends to obscure basic radical moral differences. To suggest that these are just indeterminate expressions of the basic moral law blurs a crucial way in which our judgments of good and evil are relative. ${ }^{22}$

There are two more basic difficulties with Thomistic natural moral law theory that I would like to consider now. First, even if it is the case (contrary to what was said above) that there is basic cross-cultural universal acceptance of certain fundamental moral beliefs and/or attitudes, it would not follow that the Thomistic natural moral law ethic had been established. This agreement could be explained at least as adequately by a theological voluntarism, the kind of meta-ethic offered by Russell and Hume, or by a Deweyian kind of naturalism. Russell, for example, would not talk of an apprehension of natural moral law emanating from God. He could explain the same facts by saying that those common moral ideals are expressions of commonly held attitudes or commonly felt emotions. They express the common decisions we men make in virtue of our common interests and similar make-up. Recalling that Aquinas and Maritain must invoke the strange doctrine of "knowledge through inclination," it might well be argued that Russell's kind of theory is to be preferred because it is simpler. Applying Ockham's razor, we might naturally remark that Aquinas' "hypothesis" is one we can well dispense with.

22. This point has been made very forcibly both for morals and for art criticism by George Boas. See George Boas, Cultural Relativism and Standards, in VIsIon AND Action 112-132 (ed. by Sidney Ratner, Rutgers, 1953). 
The same point can be put differently. Because we have (if we have) a common human nature and in accordance with it make certain common moral appraisals, it does not follow that there is a natural moral law in the Thomist's sense. Even if it is true "that all men share some very vague ideas about the good for man, precisely because they are men who possess certain natural tendencies and inclinations in common," this does not serve as a proof that these shared ethical ideals are God-given rather than man-made. It does not even serve to make such a belief plausible. ${ }^{23}$ One can accept some panhuman agreement about what man's good is without being committed to Aquinas' moral philosophy. As a matter of fact, Erich Fromm makes a similar argument from a naturalistic and neo-Freudian point of view. ${ }^{24}$

It must be added that this form of "natural moral law" based on universally shared attitudes is not enough for Aquinas, for it does not establish that they are self-evident, unchanging moral laws. Thomists need a stronger basis than the unity of human nature to establish their natural moral law theory. If there is no unity or common human nature, the Thomists are clearly wrong; but if there is a unity or common nature to the human animal, it does not follow that the Thomists are right.

I suggest, finally, that the whole theory rests on the confusion between what ought to be and what is. As Hume made us realize, the statement, "Man ought not to steal," is quite different from the statement, "Man does steal." 25 Men steal when they ought not. Sentences with an "ought" in them belong to a different logical type than sentences with an "is" in them. From factual statements alone, including statements of fact about human nature, we cannot deduce or derive any "ought" statement whatsoever. Values and facts are distinct, and Aquinas and his followers are not clear about this distinction, precisely because they looked upon nature as purposive, as having some kind of moral end in itself. This conception of a purposive nature is not only false but it also serves to obfuscate the basic distinction between facts and values that is so essential if we are to understand the nature of moral argument and decision. ${ }^{26}$

23. See in this context A. I. Melden and W. K. Frankena's contributions to the symposium The Concept of Universal Human Rights, in Science, Language and Human Rights, 1 THE American Philosophical Association 167-189 (1952).

24. ERICh Fromm, Man for Himselp (New York, 1947).

25. Hume's celebrated passage occurs in Book III, Part I, Section 1 of his A Treatise of Human Nature.

26. In a brilliant and readable interpretation of the history of ideas, Professor E. W. Hall has indicated how value elements have been gradually taken out of science and how in moral reflection we have become progressively clearer about the distinction between "ought" statements and "is" statements. He also indicates how this raises philosophical problems about the validation of moral and evaluative statements. I might add that $I$ am indebted to Professor Hall for a general kind of framework in which much of my argument develops. See E. W. Hall, Modrrn Science and Human Values (Princeton, 1956). 
Now it may be felt that the last two sentences in VI are sweeping and wholly unjustified. Where have I established that nature is not purposive and where have I shown that there are no "moral facts" in a purposive nature? The basic issue, it may be felt, is simply passed over.

I do not believe this to be true; that is to say, I do not believe that my case against Aquinas' conception of the natural moral law depends on my rejection of Aquinas' metaphysics or cosmology. Indeed his and Aristotle's conception of a purposive nature seems to me at best false and at worst unintelligible, but my argument against the natural moral law theory does not turn on that belief.

It is possible, however, both to make strong arguments against this metaphysical view and to show that even if these Thomistic metaphysical claims were true, the essential puzzle about the "is" and the "ought" would remain. As Bréhier, Koyré, and others have pointed out, with the arrival of Newtonian physics and Cartesian philosophy there disappeared from the scientific outlook all consideration of purpose and value. ${ }^{27}$ An experimental psychologist like Tolman or a biologist may speak of "purposive behavior," but in Aquinas or Aristotle "purposive" and "purpose" have a very different meaning. To ask "What is Jones' purpose?" is to ask about Jones' motives or intentions (or their behavioral correlations). Now it may be the case that the distinctively philosophical parts of Descartes are a great mistake, but it will hardly be claimed that Newtonian mechanics is a mistake, though even here we must in retrospect distinguish between Newton's physics and the quasitheological and metaphysical conceptions he shares with Henry More and Raphson. "A new and fruitful scientific conception," Toulmin remarks, "is often hatched from an egg of a very different sort, and for some time fragments of its original shell may (so to say) adhere to its plumage." 28 Galileo may well have been a Platonist, but we can accept Galileo's contributions to physics without embracing his Platonism, just as we might accept Berkeley's theory of knowledge without assenting to his views about the value of tar water; Newton, in later editions of his Principia, urged certain orthodox theological views, but Newton's physical theory is logically independent of his metaphysical and theological beliefs. No physicist today would dream of arguing that Aristotelian dynamics ought to replace modern physical theory. Aristotelian physical theory, qua physical theory, is only of historical interest.

27. E. Bréhier, 2 Histoire de la Philosophie, fasc. 1, 95 ('Paris, 1929) and A. Koyré, Galileo and Plato, 4 Journal of the History of Ideas 400 (1943).

28. Stephen Toulmin, 67 Philosophical Review 572 (1958). 
And modern physical theory, as Hall has argued convincingly in his Modern Science and Human Values, does not treat nature as good or bad. Nature is not regarded as purposive, and values are not taken to be some very special and mysterious facts of nature.

I am perfectly well aware that Thomists would claim that such statements as "Nature is Purposive" and "There is a Necessary Being or an all-good God" are metaphysical statements and they are supported in a different way from scientific ones. But I do not believe (as I said in I) that this metaphysical position has been made intelligible, much less established as true. The basic difficulties about purpose or design in nature seem to me to go back at least to Hume and Kant; and I agree (and I believe most non-Scholastic philosophers would agree) with Broad's verdict: "I have seen nothing in the writings of those who have tried to rehabilitate the argument which effectively rebuts their [Hume's and Kant's] adverse verdict." 29 It is true that certain defensive moves have been made against Kant and Hume, though it seems to me that Hepburn, Anderson, O'Connor, Smart, Nagel, Watts, and Edwards have recently made decisive arguments against these Thomistic metaphysical claims. $^{30}$

I can only briefly indicate one line of argument against claiming that there is (in the relevant sense) purpose in nature. Suppose we grant that in the parts of the universe we have observed there is truly a marvelous adaptation of means to ends. From the movements in our solar system to the return of the homing pigeon and the pollination mechanisms of plants, things proceed in an amazingly orderly way. But we cannot conclude from this that the universe has in the appropriate sense either a purpose or a Designer. (It could not, of course, fail to have some design in the sense of having some structure.) ${ }^{31}$ Even if it is the case that all processes directed by intelligent creatures involve adaptation of means to ends, this does not entail that all adaptation of means to ends is the product of intelligence. What reason have we to believe that those marvelous adaptations, which are not independently known to be deliberately designed, have a design and designer or a purpose? How could we test whether the human eye, the solar system, or ants were so de-

29. C. D. Broad, Religion, Philosophy and Psychical Research 190 (New York, 1953 ).

30. Ronald Hepburn, Christianity and Paradox, ch. 9 and 10 (London, 1958); John Anderson, Design, 13 Australasian Journal of Philosophy 241-256 (1935); D. J. OConnor, An Introduction to the Philosophy of Education 115-126 (New York, $1957)$; J. C. C. Smart, The Existence of God, in New Essays in Philosophical Theology 28-46 (ed. by A. Flew and A. Macintyre); Ernest Nagel, Sovereign Reason 17-35 (Glencoe, Illinois, 1954); G. S. Watts, The Thomistic Proofs of Theism, 35 Australasian Journal of Philosophy 30-46 (1957); Paul Edwards, The Cosmological Argument, in Rationalist ANNUAL 63-77 (1959).

31. Leibniz, Discourse of Metaphysics. 
signed? What would count as a failure here and what would count as a successful test? I do not believe there is or can be a test here. If someone claims he intuits it, others can and will, with equal legitimacy, claim they do not intuit it. The very meaning of "test" will then become otiose at this juncture.

To say we can legitimately use an analogical argument at this point also gives rise to insuperable difficulties. The human eye may be like a beautifully balanced machine or a work of art in certain respects, but it is like a vegetable or rock in others. Why should we pick one analogy rather than another? If we say because one more adequately illustrates one claim rather than another, then we can say: But what independent reason have you to believe that one claim - the design claim — is the correct claim? We must then leave analogy or make another analogy, to which the same objection could be made. And there seems to be no good reason why the design claim should be accepted as the correct claim. Furthermore, what does it mean to say, "The universe has a purpose," taking "the universe" either collectively or distributively? Presumably, if "the universe" is taken distributively, "the purpose of the universe" is equivalent to the sum of all the individual purposes. But how do we sum them? What does this look like? And even if we can sum them, do we not then supposedly have some overall purpose? What would it be like for the universe to fail to have a purpose? What would have to happen or not have to happen in order for us to recognize or fail to recognize that it is true or even in any degree probable that the universe has a purpose? If, in an attempt to avoid the above difficulties, "the universe" is taken collectively, then to discover purpose in the processes in the universe would not at all prove the universe as a whole has purpose. In either event, if "purpose" is being used analogously to "purpose" in "My purpose is to take the island" or in "Jet fighters have a purpose," then our uses of "purpose" must have a minimum of one distinctive property in common. But what is this property here? And if no common property is signified by "purpose," then "purpose" is surely being used equivocally. ${ }^{32}$

These arguments are not new and they are not at all exhaustive of all the moves that can be made by both sides. They are of necessity put with exceeding brevity; if I were to expand these arguments I would merely be going over what seem to me well-worn though decisive arguments that are essentially outgrowths of Hume's and Kant's arguments, though this is not to say that they have not been tailored to meet attempted rebuttals of Hume and Kant.

32. Paul C. Hayner, Analogical Predication, 55 The Journal of Philosophy 855-62 (1958). 


\section{VIII}

This short argument and "appeal to authority" will no doubt seem unconvincing to some, but to try to say why metaphysical explanations of this type are unintelligible would involve another essay, if $I$ were to do justice to the question. But for the sake of this discussion I will grant what I believe to be contrary to fact, namely, that "Necessary Being" and "final cause" have an intelligible use. Let us also assume for the sake of the discussion that sentences like "Nature is purposive," "Man and nature have a final end," and "Men were created to worship God" are true. My crucial point is: Even if these sentences really can be used to make genuine statements that are in fact true, no normative or moral statements can be derived from them.

Philosophers who deny that we can logically derive or base a moral claim on a metaphysical position will say, as William Dennes does:

A system of metaphysics, if it were known to be the truth or the probable truth about the order of entities that constitute the universe, would of course be superbly instructive. But there is one thing it could not enable us to do logically or intelligibly, and that is to determine from what really is what really ought to be: to derive from judgments of fact, judgments of value. It could only be by taking the symbol "good" to mean precisely what it meant by "real," and nothing more than is meant by "real," that we could say that metaphysics, as a theoretic discipline, determines or demonstrates the nature of value. But then our statement, "what is metaphysically real, and only that, is good," would mean precisely what is meant by either one or other of the empty truisms: "Whatever is metaphysically real, and only that, is metaphysically real," or "whatever is good, and only that, is good." 33

33. William Dennes, Knowledge and Values, in Symbols and Values: An Initial Study 606 (ed. by Lyman Bryson, New York, 1954). Father Gallagher has replied to Dennes on this point but I do not believe he obviates the basic difficulty advanced by Dennes about deriving a moral statement from a metaphysical statement. Gallagher says, with respect to the quotation from Dennes given in the text: ". . . a Scholastic would say that every actually existing thing (that which is real - a res) is good. Even the devil, insofar as he exists according to the creatural nature God gave him, is good." But the "is" in Gallagher's two sentences is not the "is" of identity but the "is" of predication. We can deny these two statements themselves without self-contradiction; and the last one is clearly a moral judgment, and the other would be if it were not a bit of indirect discourse. ("Every actually existing thing is good" is a moral utterance.) To say "Evil, as such, is a privation and that reality, as such, is good" is to make another moral judgment and not to indicate how we could set up a metaphysic as the basis or foundation of our moral norms, even if we can understand (as I do not) what "privation" as "a deflection from his [the Devil's] original reality, in the direction of nothingness" means. Gallagher is right in saying that if we accept his moral judgments quoted above as leading moral principles or as normative defining principles of natural moral law (functioning like the ground rules of chess) then " 'good' can mean precisely what is meant by 'real" ; but Dennes' point and my point is that in ordinary moral discourse there is no such rule of language and that to make one 
Those who think they can discover what they ought to do from a discovery about "ultimate nature of reality" are tacitly assuming that what is metaphysically real or "ultimately real" ought to be done or ought to be. But it is not self-contradictory or even logically odd to say, " $\mathrm{X}$ is an ultimate reality whose nonexistence is inconceivable, but $\mathrm{X}$ ought not to be." What is ultimately real could be evil or it could be quite neutral. There is no rule of language which indicates an identity of meaning between what is real and what is good or obligatory. To make such a rule by linguistic fiat and to claim that such a linguistic fiat ought to be accepted because it gives us a clearer, more adequate foundation for morals is itself an expression of a value judgment; and if such a value judgment is made, we must for the sake of clarity give up the idea that we can derive a moral statement from purely metaphysical statements and/or metaphysical and empirical statements alone.

That many plain men infer " $\mathrm{X}$ is obligatory" from "God wills $\mathrm{X}$," " $\mathrm{X}$ is in accord with our essential human nature," "X is of the true nature of Being" and the like, indicates they have tacitly, and perhaps even unconsciously '(as in a Peirceian acritical inference) assumed "What God wills is obligatory," "What is in accord with our essential human nature is good," etc. But here these hidden premises are themselves moral judgments; the "is" in the above sentences is not the "is" of identity, and all these statements may be denied without self-contradiction.

Someone might still claim that I have not yet really met the Thomist or Aristotelian case. I have assumed a "metaphysical system" or a set of categories in which fact (including "metaphysical facts") and value are distinct, but, it might be urged, the Thomistic-Aristotelian system is denying just that, for some facts and values at least. When it is claimed that nature is purposive, there is just this conflation of fact and value. I find this claim obscure almost to the point of unintelligibility. It is the obfuscation I was complaining about at the end of VI. There seems to be no intelligible job for these words here. We cannot do the usual things with them and we do not know what new things to do except that in some exceedingly obscure way they indicate that some claim is being made about a more secure foundation for our morality.

But even if we can intelligibly indicate how the fact-value or evaluativedescriptive dichotomy does not apply to a statement like "Nature is purposive" and even if we can show that these "metaphysical realities" are at one and

is in itself to make a value judgment and not to derive moral statements from metaphysical statements about reality. See Eugene Gallagher, Comments, in Symbols AND Values: AN INITIAL Study 615 (ed. Lyman Bryson et al., New York, 1954). 
the same time facts and values, I still do not see how we can derive ordinary moral or evaluative conclusions from them.

I must explain my meaning here. Moral questions are practical questions. They occur when questions arise about what is to be done or whether what was done in the past was the thing to have done. Most paradigmatically, moral statements are used to guide conduct. ${ }^{34}$

We have a clear case of moral reasoning in Thucydides, The Peloponnesian War. (1.68 ff.) Sparta's allies come to Sparta to discuss the difficulties with Athens over Potidaea and Corcyra and to decide whether to break up the Delian confederacy and fight Athens. The question is clearly a question about what to do. Their interest in what was the case was limited to discovering those facts which would help them decide how to act. The Corinthians advised the Spartans: ". . . choose the right course, and endeavor not to let Peloponnese under your supremacy degenerate from the prestige that it enjoyed under that of your ancestors." Some Athenians, who happened to have been in Sparta, countered by bidding the Spartans "not to dissolve the treaty, or break your oaths, but to have our differences settled by arbitration according to our agreement." In weighing the considerations the majority of Spartans were for war, but their old king, Archidamus, urged peace. He warned them of their inferiority in ships and of Athens' invulnerability and advised them to "have a care that we do not bring deep disgrace and deep perplexity upon Peloponnese." He finally urged the Spartans to prepare for war but not to initiate aggression. But the Ephor Sthenelaidas (a politically astute rabble-rousing moralist) countered this and exhorted the Spartans to "Vote ... for war, as the honor of Sparta demands, and neither allow the further aggrandizement of Athens, nor betray our allies to ruin, but with the gods let us advance against the aggressors." The Spartans considered these contentions and finally with their allies decided on war. The point here is not to deny that reasoning went on and that factual considerations were involved but to point out that all of this was instrumental to arriving at a decision.

Moral problems are problems of choice, and moral reasoning is practical reasoning about how we should act. Even when we say "The Spartans were clearly wrong in declaring war" we do not make a purely theoretical statement. Rather we are saying (in effect) that the Spartans ought to have acted in a certain fashion and we imply that if we had been similarly placed we would have heeded Archidamus and not declared war. Moral questions are, necessarily, questions concerning what to do. This is the basic sense in which

34. P. H. Nowell-Smith, Eтhics 11-22, 95-104 (Baltimore, 1954); Kai Nielsen, The Functions of Moral Discourse, 7 Philosophical Quarterly 236-248 (1957); and Speaking of Morals, 2 The Centennial Review 414-44 (1958). 
a moral judgment is prescriptive, directive, or normative. ${ }^{35}$ We are only interested in what is the case to the extent that knowing what is the case is instrumental in helping us decide what to do.

With these remarks in mind, it should not be hard to see that no moral or evaluative statements follow from these so-called "fact-value statements" or from "fact-value statements" together with some plain empirical statements. If $\mathrm{I}$, as a moral agent, discover that, in some peculiar way, the "factvalue" "The Universe is purposive," is true and that $I$, as a being in the universe, have a purpose or an end, it still does not follow that I have ipso facto resolved any moral perplexity by noting how it is that I behave. The discovery that "teleological explanations" rather than "nonteleological explanations" best explain how I behave does not entail any moral conclusion.

Suppose my moral perplexity is to discover, in Kierkegaard's phrase, "How I am to live and die"; that is to say, to find out "the purpose of my existence." Now, by putting it as "What is the purpose of my existence?" I make it sound as if I were asking a question of the same logical type as "What is the purpose of my doorbell?" - a question that can admit of a clear factual answer. But though these questions have a grammatical similarity they have very different uses in human discourse. As Ayer has well said:

... what is being sought by those who demand to know the meaning of life is not an explanation of the facts of their existence, but justification. Consequently a theory that informs them merely that the course of events is so arranged as to lead inevitably to a certain end does nothing to meet their need. For the end in question will not be one that they themselves have chosen. ${ }^{36}$

My teleological discoveries will not in and of themselves resolve my problem of choice. They tell me how (in what way) I am living but they do not tell me how $I$ am to live and die. "X has such and such end" does not entail "Do X." When a perplexed person asks: "What is the meaning of life?" he is almost always asking a practical question. He is trying to decide what he is to do, and he is only interested in knowing what is the case to the degree that a certain understanding is essential for any action. It is an answer to this practical question that his "soul longs after, as the African desert thirsts for water." 37 But no general description of the world, no causal explanation - teleological or otherwise - entails an expression of a decision; and the

35. R. M. Hare, Universalisability, ARistotelian Society Proceedings 295-312 (1954-55).

36. A. J. Ayer, The Claims of Philosophy, 7 Polemic 24 (1947).

37. Soren Kierkegaard, in A KierkegaArd Anthology 4-5 (ed. by Robert Bretall, Princeton, 1951). 
language of purpose, as used in moral discourse (though not necessarily in philosophical interpretations or morality), is a bit of practical discourse in which the key expressions function to express decisions, intentions and the like. They describe as well, but shorn of this expressive or performatory use the utterances are without normative or prescriptive import.

This same general point can be made in another way. When "Life has a purpose" is taken as a physical or metaphysical explanation or description of human behavior and not as an expression of an attitude or of an intention to act in a deliberate, responsible, self-conscious manner, no moral decision or resolution to a practical problem is entailed by the discovery that $\mathrm{I}$ am "purposing" or moving to my natural end. If my behaving teleologically is just something that happens to me by virtue of my being a human being, then it cannot also function prescriptively. And this tautology has a point because it marks a distinction in the uses of language.

Since taking a moral position necessarily involves the making of a decision, I (as a moral agent) still will have to decide and resolve to seek this end that I notice human beings in fact seek. I must make, by a moral decision, this purpose or end (including my purpose or end, so metaphysically defined) $m y$ purpose or end. But this is something I must, as a mere matter of the logic of the situation, choose or decide to do. I cannot just infer it, observe it, or grasp it by some "intellectual intuition of being." I may see or notice purpose in the metaphysical sense; but until I have, by my own free resolution, decided I should act on this information, $I$ have not arrived at any moral conclusions.

I cannot derive (1) "This is my purpose" or "This is my goal" taken as expressions of decisions from (2) "This is my purpose" or "This is my goal" taken as a metaphysical statement of some odd "value-fact." But since it is very easy to confuse the metaphysical statement (2) with the moral pronouncement (1), we tend to think that if (2) is true we have answered our practical question about what I am to do and how I am to live and die. Since the words "purpose" and "end" get redefined in (2) they can now be used so that purpose could exist even if no people were making decisions or resolutions and the like. On the metaphysical interpretation, "The purpose of my life is. . ." is treated very much like "My life expectancy is. . ." But in ordinary discourse "The purpose of my life is. .." is used primarily not to state a fact but to announce a policy. To ask "What is the purpose of my existence?" is to ask "What ought I to do?" This is a practical question about what to do and does not involve us in any metaphysics at all.

When we think we can derive moral conclusions from the metaphysical statement that "Human life, and therefore my life, has a certain purpose," 
we transfer the ordinary moral meaning of "purpose" onto the metaphysical statement, making the metaphysical statement into (among other things) an expression of a decision. The metaphysical statement in effect redefines "purpose" but the redefinition is leaky; the old use sneaks back in and gives the analysis far greater plausibility than it in fact has. ${ }^{38}$ But the metaphysical statement is not meant to be such a practical utterance, and "purpose" on the metaphysical use will not bear such a burden.

It may be replied, "But it really will, and metaphysical statements have their practical uses too. That is the small grain of truth in the contention that 'metaphysics is disguised poetry." But then it must also be admitted that, so used, the metaphysical statement (2) can no longer be understood as presupposing that it makes sense to speak of the purpose of human beings apart from what attitudes they adopt, what intentions they express, or what decisions they make. To say "Life has a purpose even though no one thinks so or cares about anything" will no longer make sense except as a moral expression of intention on the part of the user. But I should think a Thomist would want very much to argue that life does have a purpose even though no one thinks it does or makes any resolutions. The natural moral law, on a Thomistic interpretation, is not a summary expression of our most pervasive and basic decisions. If some super Communists or super Fascists did some very thorough super brainwashing, all of us might come to believe that life has no purpose, existence no end. We might all come to believe that we die and rot and do what we do because in some basically arbitrary way we have been so stimulated, but Thomists would argue that even in such a malebolge the natural moral law would still obtain. Even if the super Communists or super whatnots became trapped by their own propaganda and no one even dimly understood Life's purpose, life would, in such a view, still have a purpose. Such a Brave New World situation is conceivable; but even if it did obtain, the unwritten Laws of God would remain in force: human existence - the Thomists would say - would still have its original and distinctive purpose, for the natural moral law is something ordained by God, not something made by man. Maritain repeatedly warns us that man is not the measure of good and evil, and man is not the measure of "the purpose of men"; rather, man dimly apprehends the natural moral law and the purpose of his existence, and this purpose would exist even if no one thought it existed. But if what I said above is correct, such a view cannot be true.

38. See Ronald Hepburn on "leaky redefinitions" in Ronald W. Hepburn, Literary and Logical Analysis, 8 The Philosophical Quarterly 342-57 (1958). 


\section{IX}

I have tried to state and appraise the Thomistic theory of natural moral law. My central criticisms of the theory occur in VI; VII and VIII are primarily directed to those who may feel my last criticism in VI would not hold if the universe has purpose or design. I have contended there is no good reason to believe the universe has this purpose; and even if there were this purpose, we still could not derive moral conclusions from this true statement about our world or from observations of human behavior. But even if all this is rejected, my other three criticisms remain.

It is perhaps natural for someone to reply to my arguments in VIII : "Aren't you really ringing changes on what G. E. Moore called the 'naturalistic fallacy'; aren't you really just showing that evaluations are evaluations and descriptions are descriptions and that, as long as human discourse has the functions it has, we cannot reduce the one to the other, though we can point out that certain words and sentences can, and do, function both descriptively and evaluatively?" And the answer to this is "Yes."

But then an interlocutor might remark: "To be clear we must accept this, but isn't it also clear that if 'good' is to have any meaning at all - and surely it has - it must be connected with what human beings in their rational moments strive for, desire, or need? If good isn't what reasonable human beings really want when they understand their place in nature and the causes and consequences of their desires and their distinctively human qualities, pray tell what is it or what can it be? If we really come to understand 'what man is for,' will we not come to understand - - all subtleties about the 'is' and the 'ought' aside - what is really good and what we really ought to do? Now isn't it the case that honest and reasonable men could claim the contrary only in their studies?"

And once again I would want to say "yes," but I would also want to block some very mistaken inferences from this that the Thomists make and to make some crucial and hardheaded qualifications to this. I attempted to do this in VI, but let me make it perfectly clear that I am not in the least suggesting that all is dross in Aquinas. It is abundantly clear that he is one of the great moral philosophers. Calling attention to the importance of understanding ourselves and our place in nature in determining what we ought to do is a permanent and useful insight of the Thomistic-Aristotelian tradition, though I think in connecting it with the rational commands of the Deity this insight has been badly blurred. 
If we are to gain a firm understanding of the foundations of morality, it is necessary to explain and note the mistaken inferences and to make clear the necessary qualifications. Three of these might be re-emphasized here:

1) "What are people for?" - though linguistically similar to "What are chairs for?" or "What is the liver for?" - is very different from either of these quite different questions. I have contended that there is no good reason to believe there is a Designer. If there is no Designer, "What are people for?" would not have an answer like "What are chairs for?" There would be no room for the answer: "People were made for ..." I have also argued that there is no clear evidence from the sciences of man, presently at least, that justifies our saying "What are people for?" has an answer like "What is the liver for?" From a scientific point of view it has been denied that we can speak meaningfully of "the nature of human nature."

2) Even if there is, as Sartre reminds us, human nature a posteriori but no "essence" of man, may not man, as Nietzsche said, be something to be surpassed; or may it not be the case, as D. H. Lawrence seems at times to suggest, that we ought to seek to destroy or at least submerge that which is distinctively human and firmly fix ourselves in our animal ancestry? I do not, of course, wish to urge either of these positions, but I do wish to point out that they are intelligible and that we cannot refute them by simply pointing to what people want or to what is normal, assuming (as we cannot in fact) that there are clear cross-cultural criteria for "normalcy." And it is just here that the importance of the features centering around the "naturalistic fallacy" becomes relevant; reflection on Moore's distinctions should make us realize that in morals, after we weigh up all the considerations for and against something, it still must be the case that we as moral agents must decide what is good and evil. (The force of "must" in both occurrences is logical.) The existentialists have dramatized this fact about the moral life in a very misleading way, but Ayer, Hare, and Nowell-Smith have recently made us see how this is a logical truth about the functions of normative discourse.

3) Even if there is an anthropologically confirmed "core" to the human animal and a notion that man has a distinct function, this would in no way serve to establish the Thomistic theory of the natural moral law. Such "natural good" would be quite explicable on a theory like Dewey's or Fromm's, and it is equally compatible with the kind of rational ethic articulated by Toulmin, Nowell-Smith, and Baier. It is even compatible with Russell's or Hume's theory. And some of these theories have the advantage of making far fewer assumptions than does the natural moral law theory. If there is no "core to the onion," the natural moral law theory is wrong; but if there is, it 
does not at all follow that the natural moral law theory is right or even probable.

Finally, I want to make it clear that I see no good reason to say that if a theory like Aquinas' and Maritain's is unsound the foundations of morality totters, throwing us into the "night of subjectivity." Even if Hume, Russell, and Ayer in their analyses of morality are right, it still does not follow that there can be no rationality to the moral life. ${ }^{39}$ There is no good reason at all to say, "If there is no God, then everything is permitted." This is in itself a moral judgment; it can be denied without self-contradiction, and there are those who in the name of morality would deny it. In a perfectly plain sense, some moral judgments can be justified and some objective moral appraisals can be made. ${ }^{40}$ Rejection of the Thomistic ethical theory need not entail nihilism, cynicism, subjectivism, or relativism. And it does not even entail that there are no "natural moral goods." A recognition of the unsoundness of the Thomistic natural moral theory does not make the moral life or the life of reason impossible, but should, if correct, further it. And this should be a blessing for the man who, in W. D. Falk's phrase, is committed to the principle of nonevasive living.

39. I have tried to show how Russell's analysis does not involve these nihilistic and irrational implications in my forthcoming article, Bertrand Russell's New Ethic, Methodos. 40. This has been ably argued by Stephen Toulmin, An Examination of the Place of Reason in Ethics (Cambridge, England, 1951); and by Kurt Baier, The Moral PoINT OF VIEW (Ithaca, 1958). I have tried to argue for this myself in my Justification and Moral Reasoning, 9 Mertodos 98-111 (1957); The Functions of Moral Discourse, 7 Philosophical Quarterly 236-248 (1957); Good Reasons in Ethics, 24 Theoria 9-28 (1958); and in my forthcoming article, The Good Reasons Approach and Ontological Justifications of Morality, to be published in The Philosophical Quarterly. 